\title{
Multichannel Boron Doped Nanocrystalline Diamond Ultramicroelectrode Arrays: Design, Fabrication and Characterization
}

Raphael Kiran $^{1, *}$, Lionel Rousseau ${ }^{2}$, Gaëlle Lissorgues ${ }^{2}$, Emmanuel Scorsone ${ }^{1}$, Alexandre Bongrain ${ }^{2}$, Blaise Yvert ${ }^{3}$, Serge Picaud ${ }^{4,5}$, Pascal Mailley ${ }^{6}$ and Philippe Bergonzo ${ }^{1}$

1 CEA-LIST, Diamond Sensors Laboratory, Gif-sur-Yvette 91191, France;

E-Mails: emmanuel.scorsone@ cea.fr (E.S.); philippe.bergonzo@cea.fr (P.B.)

2 Université Paris Est, ESYCOM EA2552, ESIEE Cité Descartes, BP99, Noisy Le Grand 93162, France; E-Mails: 1.rousseau@esiee.fr (L.R.); g.lissorgues@esiee.fr (G.L.); a.bongrain@esiee.fr (A.B.)

3 Institut des Neurosciences Cognitives et Intégratives d'Aquitaine (INCIA), Université de Bordeaux, UMR 5287, Bordeaux 33000, France; E-Mail: blaise.yvert@u-bordeaux1.fr

4 INSERM, U968, Institut de la Vision, Paris 75012, France; E-Mail: serge.picaud@inserm.fr

5 UPMC, Institut de la Vision, Université Paris 06, UMR_S968, Paris 75012, France

6 CEA-LITEN-DTS, Laboratoire de Stockage de l'Electricité, Le Bourget du Lac 73377, France;

E-Mail: pascal.mailley@cea.fr

* Author to whom correspondence should be addressed; E-Mail: raphael.kiran @ cea.fr;

Tel.: +33-16-908-2756; Fax: +33-16-908-7819.

Received: 24 April 2012; in revised form: 23 May 2012 / Accepted: 4 June 2012 /

Published: 7 June 2012

\begin{abstract}
We report on the fabrication and characterization of an $8 \times 8$ multichannel Boron Doped Diamond (BDD) ultramicro-electrode array (UMEA). The device combines both the assets of microelectrodes, resulting from conditions in mass transport from the bulk solution toward the electrode, and of BDD's remarkable intrinsic electrochemical properties. The UMEAs were fabricated using an original approach relying on the selective growth of diamond over pre-processed 4 inches silicon substrates. The prepared UMEAs were characterized by cyclic voltammetry (CV) and electrochemical impedance spectroscopy (EIS). The results demonstrated that the electrodes have exhibited a very fast electrode transfer rate $\left(\mathrm{k}_{0}\right)$ up to $0.05 \mathrm{~cm} \cdot \mathrm{s}^{-1}$ (in a fast redox couple) and on average, a steady state limiting current (in a $0.5 \mathrm{M}$ potassium chloride aqueous solution containing
\end{abstract}


$1 \mathrm{mM} \mathrm{Fe}(\mathrm{CN})_{6}{ }^{4-}$ ion at $\left.100 \mathrm{mV} \cdot \mathrm{s}^{-1}\right)$ of $1.8 \mathrm{nA}$. The UMEAs are targeted for electrophysiological as well as analytical applications.

Keywords: ultramicroelectrode; boron doped diamond; electrochemical impedance spectroscopy; biosensor array; statistical study of microelectrode arrays

\section{Introduction}

Microelectrodes exhibit significant advantages over macro-electrode systems, such as a decreased ohmic drop, hemispherical diffusion layer, which extends into the solution, fast establishment of a steady-state signal, and higher $\mathrm{S} / \mathrm{N}$ ratio. Moreover, they require very small sample volumes [1]. Several multi-electrode arrays systems have been reported elsewhere, where all microelectrodes are connected together to form one single probe $[2,3]$. Those electrodes, when designed appropriately, still behave as individual microelectrodes at suitable scan rates, but since they are all interconnected they offer other advantages such as an enhanced electrical signal when compared to single electrodes. On the other hand, boron doped diamond (BDD) materials exhibit superior electrochemical properties over other conventional electrode materials including low capacitive background currents, wide potential window in aqueous media and corrosion resistance in harsh environments [4-6]. Thus the advantage of using MEAs over macro-electrodes has been further improved by combining their unique properties resulting from geometrical characteristics with the excellent electrochemical properties of BDD materials [7-10]. Diamond MEAs were used for electro-analytical applications such as, for example, the detection of catecholamine [11]. BDD MEAs were also used to study the formation of different species at the electrode surface, investigated by scanning electrochemical microscopy, such as the peroxodisulfate [12]. To enable the patterned growth of diamond, we had anticipated the approach that was to be used and reported it in reference [13]. However, a step-by-step optimization of the fabrication process has appeared necessary to enable the electrodes to offer the required performances. Here, we have now a clearer view of the best passivation layer that was compatible with the entire process and that offer the required electrode performances. Further we believe our process to be more likely to be compatible with standard fab plants as it avoids diamond etching steps often seen as a limitation for process transfer due to reactor contamination issues.

Several other approaches to fabricate interconnected and individually addressable diamond MEAs were previously described in the literature: Hess et al. have reported on fabrication and characterization of a 10 channel diamond on polymer MEA [14], Gao et al. on a four channel MEA to detect catecholamine [15]. However for electrophysiological applications, much more miniaturized electrodes are desirable to facilitate more channel of communication. To the authors' knowledge there is no report on fabrication and characterization of BDD micro-electrode arrays (MEA) and ultra-MEA (UMEA) for systems consisting of an array of 64 multiple electrodes or more, where each electrode is individually connected to a single electrical connector and towards a multichannel readout system. Such systems appear extremely useful for electrophysiology applications, where they are used to record the neural signals simultaneously on a 2D network of a cell line culture, a neural tissue or an embryonic organ [16]. Noble metals like platinum [17] and gold [18], as well as silicon [19] 
microelectrodes have a long history as neural electrodes for electro-analytical systems, but suffer somehow from long term stability. Wang et al. have also reported on functionalized hydrophilic carbon nanotube (CNT) microelectrode arrays as a novel prototype neural interface owing to their high charge injection limit [20]. However, some groups have reported on the cytotoxicity of CNTs and hence the biocompatibility issue, especially during long term in-vitro measurements, remains an issue to address [21]. Titanium nitride and iridium oxide microelectrodes are extensively used for electrophysiological applications for their enhanced charge injection limit [22]. Although these materials possess high capacitance, the reduced potential window and high background current limit their use in electroanalytical applications. BDD, because of its unique properties appears as a promising alternative material for individually addressed MEAs, and in particular its bio-inertness [6], corrosion resistance and long term stability offer novel interests for electrophysiology applications. Moreover, the electrochemical intrinsic properties of BDD as well as its carbon nature enables covalent immobilization of functional groups such as enzymes, DNA, etc. onto the electrode surface [23], further adding highly valuable properties for analytical applications, with the possibility to e.g., selectively anchor antibodies to localize cells. Non-invasiveness, long term and multichannel recording ability makes BDD UMEA the ideal tool for in-vitro pharmacology drug research. For example, in-vitro electrophysiological response of neural tissues, upon contact with toxic compounds, can be studied using MEA [16]. Another attractive feature of UMEAs is that they can be employed to detect some electroactive species at low concentration and even in the absence of a supporting electrolyte [1,24] since in this particular case the ohmic drop issues get minimized because of the small current range used in such UMEA systems.

Various approaches have been reported in the literature to fabricate BDD MEA and are generally based on standard photolithography techniques along with selective Reactive Ion Etching (RIE) etching of diamond coating [25-27]. We report herein a different technological process for the fabrication of diamond UMEAs, which involves the selective growth of diamond over silicon substrates, followed by the deposition of metal contacts and passivation layers. Microelectrodes exhibit sigmoidal voltammetric curves rather than the peak behavior as observed on macro-electrodes. This sigmoidal behavior is due to steady-state diffusion of species from the liquid to the very small area electrode, whereas on macro-electrodes, the peak behavior is associated with the linear diffusion-limited transport of analytes. The smaller the surface area of the electrode, the better the mass transport towards the active area because of hemispherical diffusion [28-30]. Here we have used electrochemical (EC) characterization techniques such as cyclic voltammetry (CV) and electrochemical impedance spectroscopy (EIS) to appreciate the electrodes performances namely their limiting currents $\left(i_{\text {lim }}\right)$, electron transfer rates $\left(\mathrm{k}_{0}\right)$, electrochemical windows and background currents $\left(\mathrm{i}_{\mathrm{BG}}\right)$ etc. They are the most efficient techniques to detect any cracks or discontinuity of the insulating layer and analyzing EC properties of individual BDD UMEs. 


\section{Experimental Section}

\subsection{UMEA Fabrication}

A process was optimized to allow the fabrication of $8 \times 8$ diamond UMEAs with diamond electrodes of $14 \mu \mathrm{m}$ in diameter and $100 \mu \mathrm{m}$ of inter-electrode pitch. At first, detonation diamond nanoparticles were spread onto a pre-oxidized 4 inches silicon wafer using a process described by Scorsone et al. [31]. Next, an aluminum hard mask, composed of 8 by 8 plots of 40 micrometer in diameter each, was deposited over the electrode areas by photolithography and the diamond nanoparticles outside these protected areas were etched away using ultra short oxygen plasma. The metal hard mask was then chemically removed to reveal the diamond nanoparticles patterns, on which diamond electrodes were grown in an MPECVD diamond growth reactor (Seki AX6500) with a gas mixture of methane, hydrogen and trimethylboron at typically $800{ }^{\circ} \mathrm{C}$. The fabricated diamond electrodes exhibit a thickness of approximately $300 \mathrm{~nm}$ over 40 micrometers in diameter. The electrodes were then individually contacted by the deposition of Ti $(50 \mathrm{~nm}) / \mathrm{Pt}(150 \mathrm{~nm})$ metal tracks using the lift-off process and Clariant Nlof 2020 as photoresist material. Contact on the electrodes was achieved by deposition of a metal ring across the edges of the electrodes. Finally a $600 \mathrm{~nm}$ thick silicon nitride $\left(\mathrm{Si}_{3} \mathrm{~N}_{4}\right)$ layer was deposited by $\mathrm{CVD}$ onto the substrate in order to isolate the metal tracks from the electrolyte solution. Several insulating passivation layers were tested, including photo-resist SU-8, silicon oxide etc., but leakage capacitive and/or faradic current were observed. $\mathrm{Si}_{3} \mathrm{~N}_{4}$, having almost twice the dielectric constant of $\mathrm{SiO}_{2}$, was chosen as the passivation layer because of lower leakage current and high resistance to oxidation [32]. The thickness of passivation layer was chosen based on trial and error in order to minimize the leakage current. Openings of the contact areas and of the diamond electrodes were achieved using local etching of the $\mathrm{Si}_{3} \mathrm{~N}_{4}$ layer by RIE with $\mathrm{SF}_{6}$ gas. It is this process step that determined the final diameter of each individual diamond electrode forming the UMEA. Finally the photoresist used to selectively etch the nitride layer was removed and the UMEA was diced using a diamond saw. The detailed fabrication process is depicted in Figure 1.

Figure 1. Schematics of diamond ultramicroelectrode array fabrication process.

Nanoseeding

$x x x x x x x x x x x x x x x x x x x x x x x x x x x x$

Metal deposition

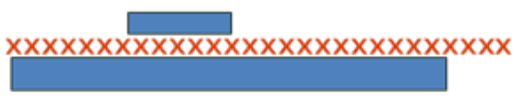

Nano seeding etching

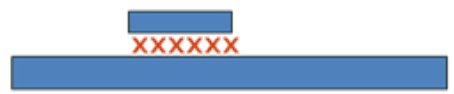

Diamond growth

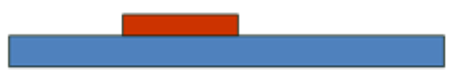

Annular metal deposition

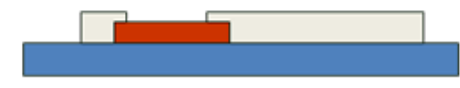

$\mathrm{Si}_{3} \mathrm{~N}_{4}$ passivation layer

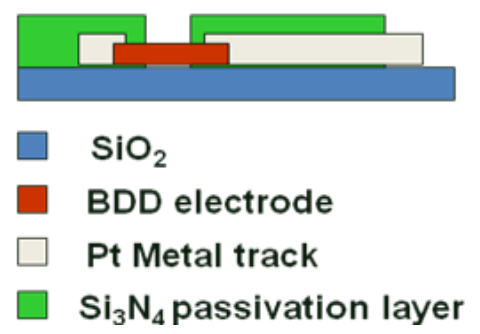


Several UMEAs with diameters varying from $2 \mu \mathrm{m}$ to $25 \mu \mathrm{m}$ have been fabricated using this technique. Most of these electrodes exhibited typical BDD responses. The complete EC characterization of one such UMEA (with $14 \mu \mathrm{m}$ diameter) is discussed in detail.

\subsection{Apparatus for EC Characterization}

All the EC characterizations were carried out using an Autolab PGSTAT 302 potentiostat. A three electrode setup consisting of the BDD UME as working electrode, a platinum wire mesh as counter electrode and an $\mathrm{Ag} / \mathrm{AgCl}(3 \mathrm{M} \mathrm{KCl})$ reference electrode was employed in the experiments. For EIS, the $\mathrm{Ag} / \mathrm{AgCl}$ electrode was replaced by a Pt pseudo-reference. EIS was recorded over a frequency range of $50 \mathrm{kHz}-0.1 \mathrm{~Hz}$ with logarithmic point spacing and potential amplitude of $0.01 \mathrm{~V} \cdot \mathrm{rms}$, while the BDD electrode was maintained at open circuit potential. $\mathrm{k}_{0}$ was determined from the Nyquist plot fitted using the ZSimWin 3.21 software.

\subsection{Reagents}

Ultrapure deionised (DI) water (Millipore Direct Q3) was used for all solutions. EIS was performed in an aqueous solution containing $0.5 \mathrm{M}$ potassium chloride (Acros Organics) and $1 \mathrm{mM}$ of potassium ferricyanide(III) and of potassium hexacyanoferrate(II) trihydrate (both from Acros Organics). $0.5 \mathrm{M}$ lithium perchlorate (Sigma Aldrich) aqueous solution was used as the electrolyte for the measurement of the potential window. The steady state limiting current plateau was observed in a $0.5 \mathrm{M}$ potassium chloride aqueous solution containing $1 \mathrm{mM} \mathrm{Fe}(\mathrm{CN})_{6}{ }^{4-}$ ion while the electrodes were scanned at $100 \mathrm{mV} \cdot \mathrm{s}^{-1}$ from $0.05 \mathrm{~V}$ to $0.45 \mathrm{~V} v s$. $\mathrm{Ag} / \mathrm{AgCl}$. The electrode electron transfer rate $\mathrm{k}_{0}$ is defined as [33]:

$$
\mathrm{k}_{0}=\mathrm{RT} / \mathrm{n}^{2} \mathrm{~F}^{2} \mathrm{SR}_{\mathrm{T}} \mathrm{C}_{0}
$$

where $\mathrm{R}$ is the universal gas constant, $\mathrm{T}$ the absolute temperature $(\mathrm{K}), \mathrm{S}$ the surface area of the electrode $\left(\mathrm{cm}^{2}\right)$, F Faraday's constant $\left(96,500 \mathrm{C} \mathrm{mol}^{-1}\right), \mathrm{R}_{\mathrm{T}}$ the electron transfer resistance of the electrode $(\mathrm{ohm}), \mathrm{C}_{0}$ the concentration of redox couple $\left(\mathrm{mol} \mathrm{cm}{ }^{-3}\right)$, and $\mathrm{n}$ the number of electrons transferred. The limiting current $i_{\text {lim }}$ is given by the following equation [34]:

$$
\mathrm{i}_{\text {lim }}=4 \mathrm{nrFDC}
$$

where $\mathrm{n}$ is the number of electrons transferred, $\mathrm{r}$ the radius of the electrode, $\mathrm{D}$ the diffusion coefficient of $\mathrm{Fe}(\mathrm{CN})_{6}{ }^{4-}$, and $\mathrm{C}$ the bulk concentration of the species. Unless stated otherwise the potential is given versus an $\mathrm{Ag} / \mathrm{AgCl}$ reference electrode through the paper.

\section{Results and Discussion}

Figure 2(a) shows the SEM image of the $8 \times 8$ UMEA along with the tracks, where one can observe that each electrode is well separated (100 $\mu \mathrm{m}$ pitch). The diamond crystals are highly faceted, with an average grain size of $100 \mathrm{~nm}$, as seen in Figure 2(d) at higher magnification. Here neither major cracks nor pin-holes were visible, under SEM or optical microscopy, nor on the tracks, nor on the passivation layer nor on the electrode surface as seen in Figure 2(b,c). The electrode surface appears bright in SEM owing to the fact that the surface is conductive in steady state with respect to the outer passivation. In fact the observed surface conductivity may be associated to the hydrogen $(\mathrm{H})$ termination of the 
electrode surface just after growth. A negative electron affinity is generated on the $\mathrm{H}$ terminated surface which increases the density of the back scattered electron [35]. The electron affinity of an $\mathrm{H}$ terminated diamond surface can go up to $-1.3 \mathrm{eV}[35,36]$.

Figure 2. SEM image of an $8 \times 8$ UMEA along with the tracks (a) and magnified SEM image of a single electrode (b, $\mathbf{c}$ and $\mathbf{d})$.

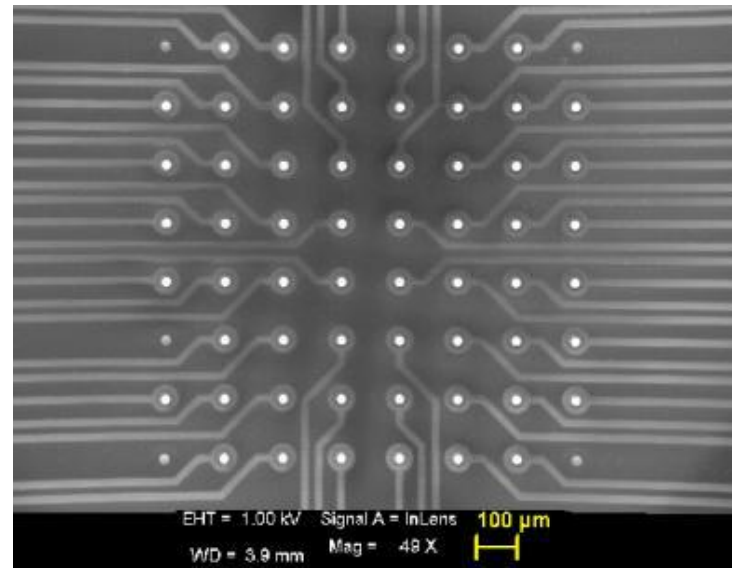

(a)

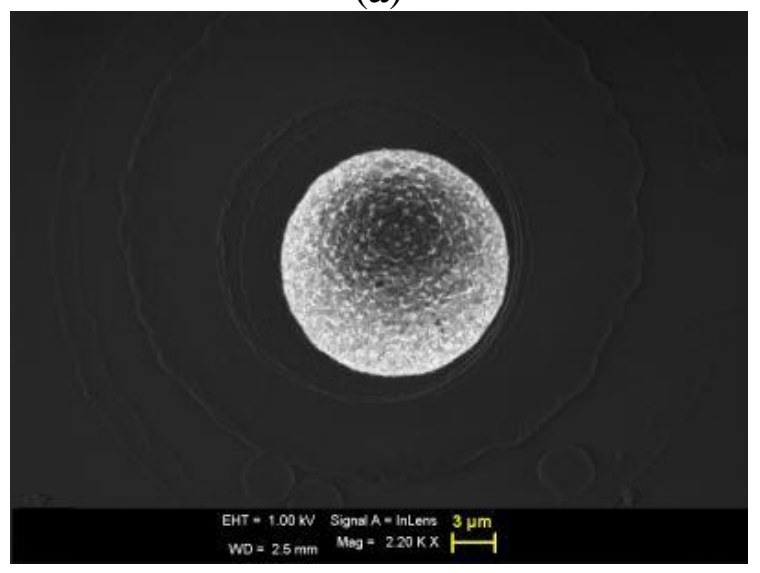

(c)

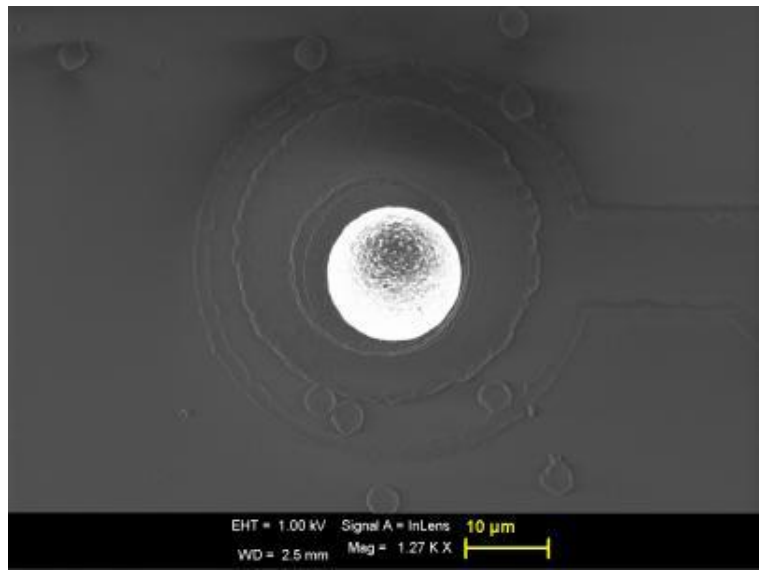

(b)

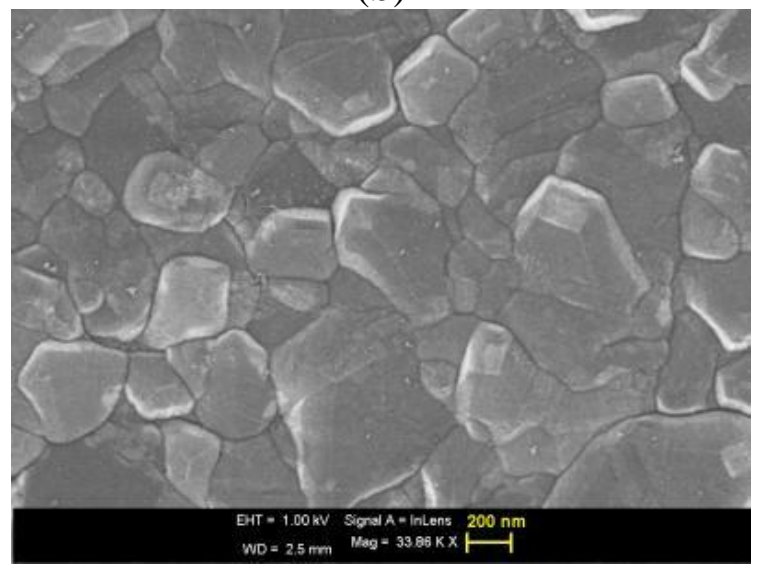

(d)

$\mathrm{CV}$ was recorded on all the electrodes in aqueous $\mathrm{LiClO}_{4}$ solution to ascertain the accessible EC window. Most of the electrodes exhibit a typical BDD window of over $3 \mathrm{~V}$ (in aqueous solution). $\mathrm{CV}$ of one such electrode is shown in Figure 3(a) where the electrode was scanned at $200 \mathrm{mV} \cdot \mathrm{s}^{-1}$. One unexpected characteristic appeared on this first prototype, as several electrodes exhibited the typical potential window of platinum electrodes. They will be made visible on the following Figures 3(b), 4(b) and 5(b) as white spots, although of course they could be fully characterized but not relevant with the properties of diamond. This was associated with cracks or pinholes in the passivation layer so that the platinum tracks were in contact with the electrolyte. This, although, not observed with imaging techniques becomes easily identified with EC characterization. Other technique to detect the cracks or pinholes is fluorescence confocal laser scanning microscopy as demonstrated by Rudd et al. on platinum UMEA [37]. During CV characterization of each electrode, a transient current flows within the potential window when the potential is varied, as the ions move to the surface forming a double layer [38]. The charging and discharging of this double layer constitute to the background current within the potential window. The background current $i_{B G}$ was calculated for the electrodes of the array 
and was observed to be $94 \pm 65 \mathrm{pA}$ at a scan rate of $200 \mathrm{mV} \cdot \mathrm{s}^{-1}$. $\mathrm{i}_{\mathrm{BG}}$ of the $8 \times 8$ matrix is depicted in Figure 3(b). RGB color model was used to indicate the amplitude of $i_{\mathrm{BG}}$ of each electrode. The green and blue color component has a value $=0$ and red component vary from 0 to 255 corresponding to the amplitude of $i_{\mathrm{BG}}$. The darker the spot, the higher the background current.

Figure 3. (a) Potential window observed by cyclic voltammetry (scan rate $=200 \mathrm{mV} \cdot \mathrm{s}^{-1}$ ) in $\mathrm{LiClO}_{4}$ solution where $\mathrm{i}$ is the current in $\mathrm{nA}$ and $\mathrm{E}$ is the applied voltage in volts versus an $\mathrm{Ag} / \mathrm{AgCl}$ reference electrode and (b) $\mathrm{RGB}$ model of an $8 \times 8$ electrode array where each electrode is represented by a spot and the red component value corresponds to their respective $i_{B G}$ value. (In this first prototype, and although measurable, white spots correspond to electrodes that were not exhibiting the EC window of diamond, as associated with Pt shorts from leaky tracks, thus not relevant for the comparison).

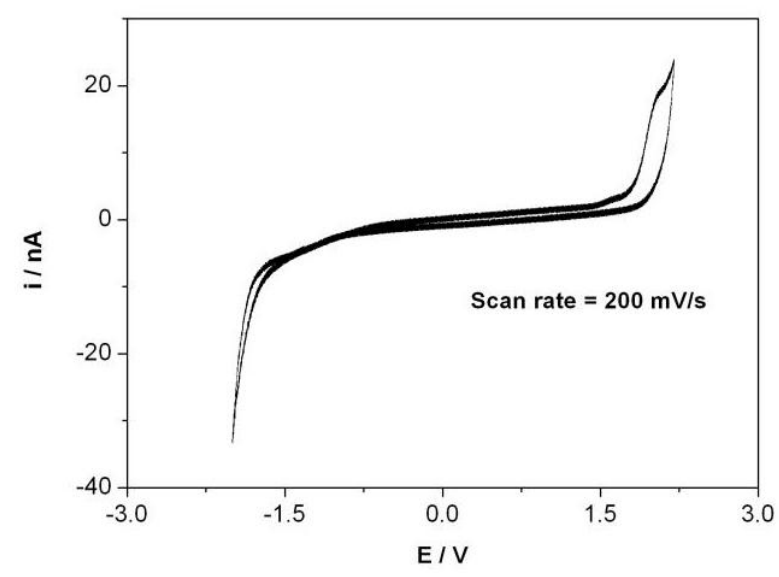

(a)

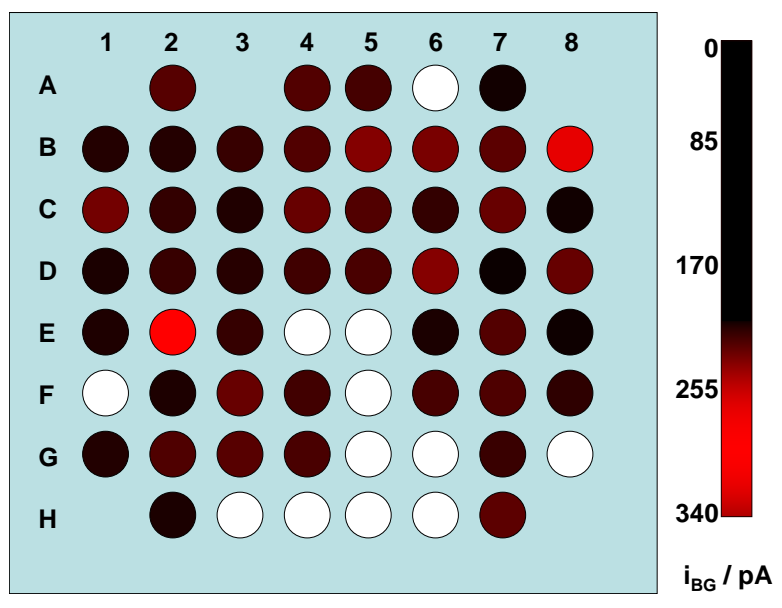

(b)

Ideally, the limiting current of a UME is independent of the scan rate $[39,40]$. The radial diffusion behavior of the UME enhances the mass transport and hence shows a sigmoidal behavior in CV. On the other hand a macro-electrode shows a peak and the value of the peak current is directly proportional to the square root of the scan rate as the planar diffusion behavior limits the current. Steady state voltammograms were recorded using $\mathrm{CV}$ in $1 \mathrm{mM} \mathrm{Fe}(\mathrm{CN})_{6}{ }^{4-}$ in $0.5 \mathrm{M} \mathrm{KCl}$ solution at $100 \mathrm{mV} \cdot \mathrm{s}^{-1}$. The limiting current $\mathrm{i}_{\text {lim }}$ of the $8 \times 8$ matrix was recorded and the average limiting current value was of $1.83 \pm 0.2 \mathrm{nA}$ as opposed to theoretical limiting current of $1.8 \mathrm{nA}$ (Diffusion coefficient of ferrocyanide $=6.67 \times 10^{-6} \mathrm{~cm}^{2} \cdot \mathrm{s}^{-1}$ [41]). Furthermore they varied from electrode to electrode with a standard deviation of $190 \mathrm{pA}$ (Table 1). Figure 4(a) shows CV of an electrode at various scan rates. When the diffusion layer $\mathrm{d}$ [given by $\mathrm{d}=(2 \mathrm{Dt})^{0.5}$ ] is greater than the electrode radius $\mathrm{r}$, radial diffusion predominates and if $r>d$, planar diffusion predominates, where $t$ is the time of experiment. At slower scan rates of 25,50 and $100 \mathrm{mV} \cdot \mathrm{s}^{-1}$ the diffusion layer thickness $\mathrm{d}>>$ radius $\mathrm{r}$ of the electrode and hence radial diffusion predominates and as a result a sigmoidal voltammogram is observed. $\mathrm{i}_{\text {lim }}$ observed at $25 \mathrm{mV} \cdot \mathrm{s}^{-1}$ was $1.6 \mathrm{nA}$ and at $100 \mathrm{mV} \cdot \mathrm{s}^{-1}$ was $1.66 \mathrm{nA}$. Although a slight deviation from the ideal scan rate independent behavior was observed, the current density variation is negligible (less than 4\%) when compared to a macro-electrode at these scan rates. Figure 4(b) represents an RGB color model indicating the value of $i_{\text {lim }}$ of each electrode where red and blue color component has a value $=0$ and green component vary from 0 to 255 corresponding to the amplitude of $i_{\text {lim }}$. 
Figure 4. (a) Cylcic voltammogram of an electrode at 25,50 and $100 \mathrm{mV} \cdot \mathrm{s}^{-1}$ in $0.5 \mathrm{M}$ potassium chloride aqueous solution containing $1 \mathrm{mM} \mathrm{Fe}(\mathrm{CN})_{6}{ }^{4-}$ ion and (b) $\mathrm{RGB}$ model of an $8 \times 8$ electrode array where each electrode is represented by a circle and the green component value corresponds to their respective $i_{\lim }$ value.

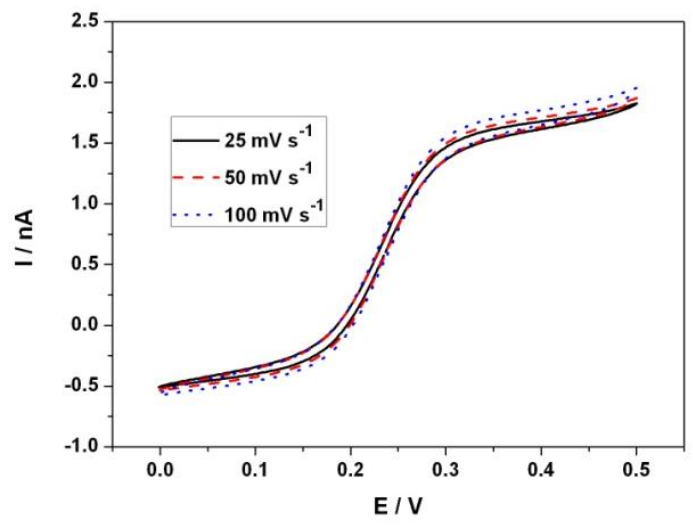

(a)

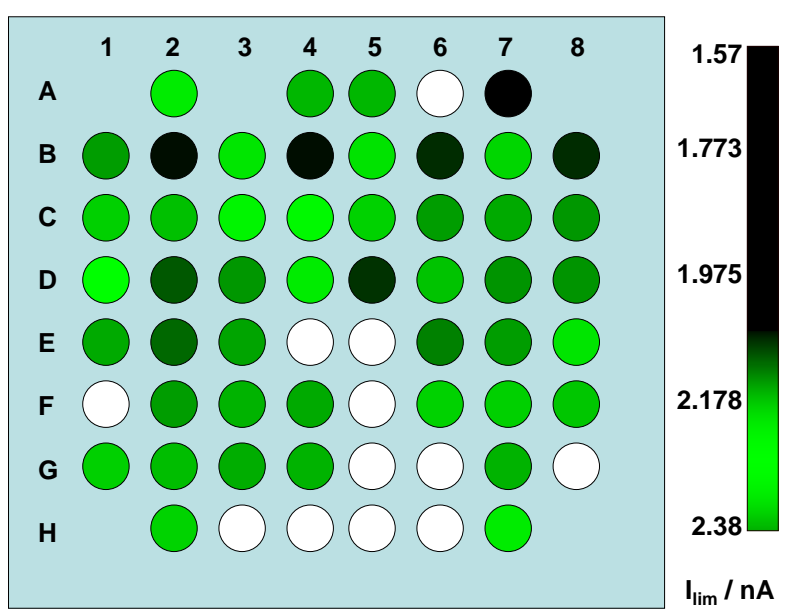

(b)

Figure 5. (a) Nyquist plot (experimental data and fitted data) of an ultramicroelectrode and (b) RGB model of an $8 \times 8$ electrode array where each electrode is represented by a circle and the blue component value corresponds to their respective $\mathrm{k}_{0}$ value.

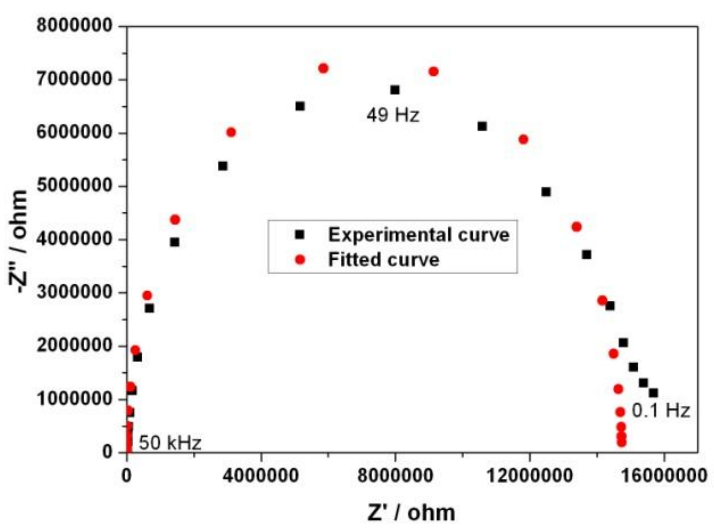

(a)

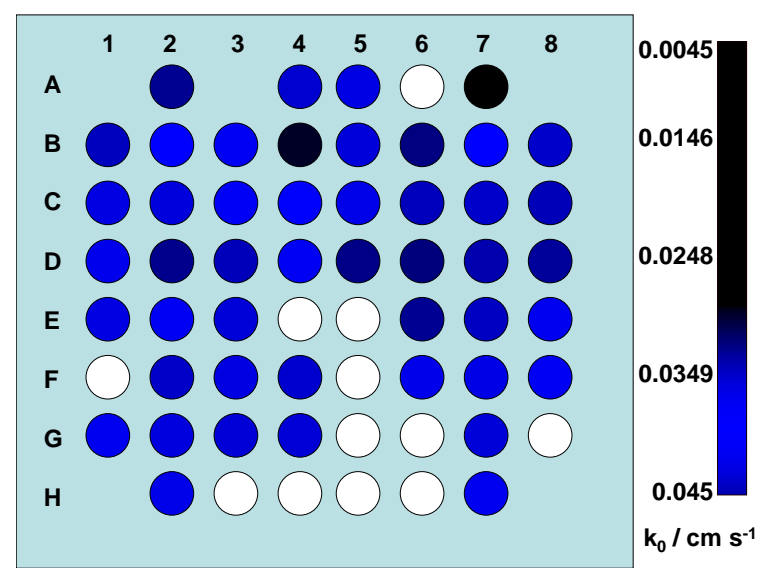

(b)

Table 1. Mean value and standard deviation of the background current $i_{\mathrm{BG}}$, limiting current $\mathrm{i}_{\mathrm{lim}}$, and transfer rate $\mathrm{k}_{0}$.

\begin{tabular}{|c|c|c|}
\hline Parameters & Mean value & Standard deviation \\
\hline $\mathrm{i}_{\mathrm{BG}}$ & $94.33 \mathrm{pA}$ & $64.85 \mathrm{pA}$ \\
$\mathrm{i}_{\lim }$ & $1.83 \mathrm{nA}$ & $0.19 \mathrm{nA}$ \\
$\mathrm{k}_{0}$ & $0.0132 \mathrm{~cm} \cdot \mathrm{s}^{-1}$ & $0.008 \mathrm{~cm} \cdot \mathrm{s}^{-1}$ \\
\hline
\end{tabular}

The Nyquist plots obtained from EIS of the UMEA were used to calculate the $\mathrm{k}_{0}$ of each electrode. An electrochemical system, represented by Randles circuit, consists of four impedance components: $R_{S}$ the electrolytic resistance, $R_{T}$ the charge transfer resistance, $C_{D}$ the double layer capacitance and $Z_{W}$ the Warburg element. The diameter of the semi-circle portion corresponds to the transfer resistance $[42,43]$. 
From the Nyquist plot of one such electrode (Figure 5(a)) it was observed that the straight line (Warburg element) almost disappeared and the plot is more semi-circular. The linear correlation of $\mathrm{Re}$ (Z) vs. -img (Z) corresponds to a diffusion limited process [44]. The rate of mass transport to and from the electrode is greater in UMEs when compared to macro-electrodes. Hence the Randles circuit of a UME gets modified to a three impedance component $\left(R_{S}, R_{T}\right.$ and $\left.C_{D}\right)$. An $R(C R)$ model circuit was used to fit the experimental curves and the impedance value obtained for $R_{S}, R_{T}$ and $C_{D}$ were 414 ohm, 14.7 Mohm and $132 \mathrm{pF}$ respectively. The $\chi^{2}$ error was suitably low $\left(\chi^{2}<10^{-4}\right)$, and the error associated with each element was less than $5 \%$. The electron transfer rate of this electrode was calculated to be $0.012 \mathrm{~cm} \cdot \mathrm{s}^{-1}$. The semicircle impedance spectra could also favorably be used for bio-sensing applications where one can observe the change in the $\mathrm{k}_{0}$ value [42]. The electrode electron transfer rate $\mathrm{k}_{0}$ is calculated using Equation (1) and variation of $\mathrm{k}_{0}$ along the electrodes in the chip is shown in Figure 5(b). The average value obtained for $\mathrm{k}_{0}$ is of $0.013 \mathrm{~cm} \cdot \mathrm{s}^{-1}$ which is close to the values reported by other groups for an $\mathrm{H}$ terminated BDD electrode [45-47]. The electron transfer rate of the electrodes was further enhanced by applying an electrochemical treatment [48]. A train of 50 current pulses of alternating amplitude $\left(10 \mathrm{~mA} \cdot \mathrm{cm}^{-2}\right.$ and $\left.-10 \mathrm{~mA} \cdot \mathrm{cm}^{-2}\right)$ and of equal duration (100 $\left.\mathrm{ms}\right)$ applied between working and counter electrodes in $0.5 \mathrm{M} \mathrm{LiClO}_{4}$ solution. After this treatment the $\mathrm{k}_{0}$ values of the electrodes have been augmented by several folds and $i_{\text {lim }}$ measured was close to theoretical values.It has been observed that the values of $\mathrm{k}_{0}, \mathrm{i}_{\mathrm{lim}}, \mathrm{C}_{\mathrm{D}}$ and $\mathrm{i}_{\mathrm{BG}}$ were proportional for most of the electrodes. The variation of these values from electrode to electrode cannot be explained by conventional EC and SEM characterization. These variations might be due to difference in intrinsic conductivity of individual grains [49,50]. This is due to differential boron intake, even at higher boron concentration, and hence the electrical and electrochemical characteristics of grains vary from one another. A comparison is made to correlate different parameters such as the $\mathrm{k}_{0}, \mathrm{i}_{\mathrm{lim}}, \mathrm{C}_{\mathrm{D}}$ and $\mathrm{i}_{\mathrm{BG}}$ of 2 electrodes and are summarized in Table 2 . The $\mathrm{k}_{0}$ and $\mathrm{C}_{\mathrm{D}}$ values were obtained from nyquist plot and the background current (which is attributed by the double layer capacitance) is higher when $\mathrm{C}_{\mathrm{D}}$ is higher. The difference in the values of double layer capacitance measured using EIS and CV is 59\% and $48 \%$ for electrode 1 and 2 respectively. The effective surface area of the electrode depends up on the roughness of the electrode and this variation might also vary the $i_{\lim }$ and $\mathrm{k}_{0}$ values of the 2 electrodes.

Table 2. Comparison of different parameters such as the electron transfer rate $\mathrm{k}_{0}$, limiting current $i_{\text {lim }}$, double layer capacitance $C_{D}$ and background current $i_{B G}$ of 2 electrodes.

\begin{tabular}{|c|c|c|}
\hline Parameters & Electrode 1 & Electrode 2 \\
\hline $\mathrm{k}_{0}\left(\mathrm{~cm} \cdot \mathrm{s}^{-1}\right)$ & 0.012 & 0.017 \\
$\mathrm{i}_{\lim }(\mathrm{nA})$ & 1.74 & 1.76 \\
$\mathrm{C}_{\mathrm{D}}(\mathrm{pF})$ & 132 & 197 \\
$\mathrm{i}_{\mathrm{BG}}$ at $200 \mathrm{mV} \cdot \mathrm{s}^{-1}(\mathrm{pA})$ & 63 & 76 \\
\hline
\end{tabular}

\section{Conclusions}

BDD UMEAs suitable for use in electrochemical sensors were prepared by a microfabrication technique. Topographical characterization and detailed electrochemical study on individual UMEs were carried out. In electrochemical tests, the UMEs exhibited low background currents, almost 
theoretical steady state limiting currents and fast electron transfer rates (close to $0.01 \mathrm{~cm} \cdot \mathrm{s}^{-1}$ ). Further improvement in these two values can be achieved through EC activation. Although several of the UMEs failed to exhibit a BDD response, those can be easily discriminated and the process is currently being improved to completely eliminate such a failure rate. The long term goal of our work is ultimately to develop biosensing platforms for the monitoring of neural activities for electrophysiology.

\section{Acknowledgments}

The authors would like to thank the French National Research Agency and the ITMO Institute for funding of part of this research via the MEDINAS project (ANR-07-TECSAN-014) and the IMPLANTS project, respectively.

\section{References}

1. Stulik, K.; Amatore, C.; Holub, K.; Marecek, V.; Kutner, W. Microelectrodes. Definitions, characterization, and applications. Pure Appl. Chem. 2000, 72, 1483-1492.

2. Niwa, O.; Xu, Y.; Halsall, H.B.; Heineman, W.R. Small-volume voltammetric detection of 4-aminophenol with interdigitated array electrodes and its application to electrochemical enzyme immunoassay. Anal. Chem. 1993, 65, 1559-1563.

3. Kounaves, S.P.; Deng, W.; Hallock, P.R. Iridium-based ultramicroelectrode array fabricated by microlithography. Anal. Chem. 1994, 66, 418-423.

4. Yano, T.; Tryk, D.A.; Hashimoto, K.; Fujishima, A. Electrochemical behavior of highly conductive boron-doped diamond electrodes for oxygen reduction in alkaline solution. J. Electrochem. Soc. 1998, 145, 1870-1876.

5. Swain, G.M. The electrochemical activity of boron-doped polycrystalline diamond thin film electrodes. Anal. Chem. 1993, 65, 345-351.

6. Panizza, M.; Cerisola, G. Application of diamond electrodes to electrochemical processes. Electrochim. Acta 2005, 51, 191-199.

7. Soh, K.L.; Kang, W.P.; Davidson, J.L.; Basu, S.; Wong, Y.M.; Cliffel, D.E.; Bonds, A.B.; Swain, G.M. Diamond-derived microelectrodes array for electrochemical analysis. Diam. Relat. Mater. 2004, 13, 2009-2015.

8. Lawrence, N.S.; Pagels, M.; Meredith, A.; Jones, T.G.J.; Hall, C.E.; Pickles, C.S.J.; Godfried, H.P.; Banks, C.E.; Compton, R.G.; Jiang, L. Electroanalytical applications of boron-doped diamond microelectrode arrays. Talanta 2006, 69, 829-834.

9. Tian, R.; Zhi, J. Fabrication and electrochemical properties of boron-doped diamond film-Gold nanoparticle array hybrid electrode. Electrochem. Commun. 2007, 9, 1120-1126.

10. Pagels, M.; Hall, C.E.; Lawrence, N.S.; Meredith, A.; Jones, T.G.J.; Godfried, H.P.; Pickles, C.S.J.; Wilman, J.; Banks, C.E.; Compton, R.G.; et al. All-diamond microelectrode array device. Anal. Chem. 2005, 77, 3705-3708.

11. Shin, D.; Sarada, B.V.; Tryk, D.A.; Fujishima, A.; Wang, J. Application of diamond microelectrodes for end-column electrochemical detection in capillary electrophoresis. Anal. Chem. 2003, 75, $530-534$. 
12. Khamis, D.; Mahé, E.; Dardoize, F.; Devilliers, D. Peroxodisulfate generation on boron-doped diamond microelectrodes array and detection by scanning electrochemical microscopy. J. Appl. Electrochem. 2010, 40, 1829-1838.

13. Bergonzo, P.; Bongrain, A.; Scorsone, E.; Bendali, A.; Rousseau, L.; Lissorgues, G.; Mailley, P.; Li, Y.; Kauffmann, T.; Goy, F.; et al. 3D shaped mechanically flexible diamond microelectrode arrays for eye implant applications: The MEDINAS project. IRBM 2011, 32, 91-94.

14. Hess, A.E.; Sabens, D.M.; Martin, H.B.; Zorman, C.A. Diamond-on-polymer microelectrode arrays fabricated using a chemical release transfer process. J. Microelectromech. Syst. 2011, 20, 867-875.

15. Gao, Z.; Carabelli, V.; Carbone, E.; Colombo, E.; Dipalo, M.; Manfredotti, C.; Pasquarelli, A.; Feneberg, A.; Thonke, K.; Vittone, E.; et al. Transparent microelectrode array in diamond technology. J. Micro-Nano Mechatron. 2011, 6, 33-37.

16. Chiappalone, M.; Vato, A.; Tedesco, M.(B); Marcoli, M.; Davide, F.; Martinoia, S. Networks of neurons coupled to microelectrode arrays: A neuronal sensory system for pharmacological applications. Biosens. Bioelectron. 2003, 18, 627-634.

17. Thiébaud, P.; Beuret, C.; Koudelka-Hep, M.; Bove, M.; Martinoia, S.; Grattarola, M.; Jahnsen, H.; Rebaudo, R.; Balestrino, M.; Zimmer, J.; et al. An array of Pt-tip microelectrodes for extracellular monitoring of activity of brain slices. Biosens. Bioelectron. 1999, 14, 61-65.

18. Liu, S.; Chen, Y.; Fang, F.; Xu, J.; Sheng, G.; Yu, H.; Liu, G.; Tian, Y. Measurement of dissolved oxygen and its diffusivity in aerobic granules using a microelectrode array. Environ. Sci. Technol. 2009, 43, 1160-1165.

19. Biran, R.; Martin, D.C.; Tresco, P.A. Neuronal cell loss accompanies the brain tissue response to chronically implanted silicon microelectrode arrays. Exp. Neurol. 2005, 195, 115-126.

20. Wang, K.; Fishman, H.A.; Dai, H.; Harris, J.S. Neural stimulation with a carbon nanotube microelectrode array. Nano Lett. 2006, 6, 2043-2048.

21. Abarrategi, A.; Gutiérrez, M.C.; Moreno-Vicente, C.; Hortigüela, M.J.; Ramos, V.; López-Lacomba, J.L.; Ferrer, M.L.; del Monte, F. Multiwall carbon nanotube scaffolds for tissue engineering purposes. Biomaterials 2008, 29, 94-102.

22. Weiland, J.D.; Anderson, D.J.; Humayun, M.S. In vitro electrical properties for iridium oxide versus titanium nitride stimulating electrodes. IEEE Trans. Biomed. Eng. 2002, 49, 1574-1579.

23. Agnès, C.; Ruffinatto, S.; Delbarre, E.; Roget, A.; Arnault, J.-C.; Omnès, F.; Mailley, P. New one step functionalization of polycrystalline diamond films using amine derivatives. IOP Conf. Ser. Mater. Sci. Eng. 2010, 16, 1-11.

24. Suzuki, A.; Ivandini, T.A.; Yoshimi, K.; Fujishima, A.; Oyama, G.; Nakazato, T.; Hattori, N.; Kitazawa, S.; Einaga, Y. Fabrication, characterization, and application of boron-doped diamond microelectrodes for in vivo dopamine detection. Anal. Chem. 2007, 79, 8608-8615.

25. Park, J.; Quaiserova-mocko, V.; Peckova, K.; Galligan, J.J.; Fink, G.D.; Swain, G.M. Fabrication, characterization, and application of a diamond microelectrode for electrochemical measurement of norepinephrine release from the sympathetic nervous system. Diam. Relat. Mater. 2006, 15, 761-772. 
26. Carabelli, V.; Gosso, S.; Marcantoni, A.; Xu, Y.; Colombo, E.; Gao, Z.; Vittone, E.; Kohn, E.; Pasquarelli, A.; Carbone, E. Nanocrystalline diamond microelectrode arrays fabricated on sapphire technology for high-time resolution of quantal catecholamine secretion from chromaffin cells. Biosens. Bioelectron. 2010, 26, 92-98.

27. Provent, C.; Haenni, W.; Santoli, E.; Rychen, P. Boron-doped diamond electrodes and microelectrode-arrays for the measurement of sulfate and peroxodisulfate. Electrochim. Acta 2004, 49, 3737-3744.

28. Soh, K.L.; Kang, W.P.; Davidson, J.L.; Wong, Y.M.; Cliffel, D.E.; Swain, G.M. Diamondderived ultramicroelectrodes designed for electrochemical analysis and bioanalyte sensing. Diam. Relat. Mater. 2008, 17, 900-905.

29. Hayashi, K.; Takahashi, J.; Horiuchi, T.; Iwasaki, Y.; Haga, T. Development of nanoscale interdigitated array electrode as electrochemical sensor platform for highly sensitive detection of biomolecules. J. Electrochem. Soc. 2008, 155, J240-J243.

30. Streeter, I.; Compton, R.G. Measuring the size distribution of microelectrodes in an array. Sens. Actuators B Chem. 2008, 130, 620-624.

31. Scorsone, E.; Saada, S.; Arnault, J.C.; Bergonzo, P. Enhanced control of diamond nanoparticle seeding using a polymer matrix. J. Appl. Phys. 2009, 106, 014908.

32. Ma, T.P. Making silicon nitride film a viable gate dielectric. IEEE Trans. Electron Devices $\mathbf{1 9 9 8 ,}$ 45, 680-690.

33. Vanhove, E.; de Sanoit, J.; Mailley, P.; Pinault, M.-A.; Jomard, F.; Bergonzo, P. High reactivity and stability of diamond electrodes: The influence of the B-doping concentration. Phys. Status Solidi A 2009, 206, 2063-2069.

34. Viet, N.X.; Ukita, Y.; Chikae, M.; Ohno, Y.; Maehashi, K.; Matsumoto, K.; Viet, P.H.; Takamura, Y. Fabrication of new single-walled carbon nanotubes microelectrode for electrochemical sensors application. Talanta 2012, 91, 88-94.

35. Nebel, C.E.; Shin, D.; Takeuchi, D.; Yamamoto, T.; Watanabe, H.; Nakamura, T. Alkene/diamond liquid/solid interface characterization using internal photoemission spectroscopy. Langmuir 2006, 22, 5645-5653.

36. Maier, F.; Riedel, M.; Mantel, B.; Ristein, J.; Ley, L. Origin of surface conductivity in diamond. Phys. Rev. Lett. 2000, 85, 3472-3475.

37. Rudd, N.C.; Cannan, S.; Bitzlou, E.; Clanl, I.; Whitworth, A.L.; Unwin, P.R. Fluorescence confocal laser scanning microscopy as a probe of $\mathrm{pH}$ gradients in electrode reactions and surface activity microscopy (CLSM) to quantify three-dimensional pH. Anal. Chem. 2005, 77, 6205-6217.

38. Qu, D.; Shi, H. Studies of activated carbons used in double-layer capacitors. J. Power Sources 1998, 74, 99-107.

39. Colombo, E.; Men, Y.; Scharpf, J.; Pietzka, C.; Dipalo, M.; Herfurth, P.; Gao, Z.; Schneider, M.; Carabelli, V.; Carbone, E.; et al. Fabrication of a NCD microelectrode array for amperometric detection with micrometer spatial resolution. Diam. Relat. Mater. 2011, 20, 793-797.

40. Caudlll, W.L.; Howell, J.O.; Wlghtman, R.M. Flow rate independent amperometric cell. Anal. Chem. 1982, 54, 2532-2535. 
41. Konopka, S.J.; Mcduffie, B. Diffusion coefficients of ferri- and ferrocyanide ions in aqueous media, using twin-electrode thin-layer electrochemistry. Anal. Chem. 1970, 42, 1741-1746.

42. Yun, Y.; Bange, A.; Heineman, W.R.; Halsall, H.B.; Shanov, V.N.; Dong, Z.; Pixley, S.; Behbehani, M.; Jazieh, A.; Tu, Y.; et al. A nanotube array immunosensor for direct electrochemical detection of antigen-antibody binding. Sens. Actuators B Chem. 2007, 123, 177-182.

43. Dumitrescu, I.; Unwin, P.R.; Macpherson, J.V. Electrochemical impedance spectroscopy at single-walled carbon nanotube network ultramicroelectrodes. Electrochem. Commun. 2009, 11, 2081-2084.

44. Siddiqui, S.; Arumugam, P.U.; Chen, H.; Li, J.; Meyyappan, M. Characterization of carbon nanofiber electrode arrays using electrochemical impedance spectroscopy: Effect of scaling down electrode size. ACS Nano 2010, 4, 955-961.

45. Fischer, A.E.; Show, Y.; Swain, G.M. Electrochemical performance of diamond thin-film electrodes from different commercial sources. Anal. Chem. 2004, 76, 2553-2560.

46. Hupert, M.; Muck, A.; Wang, J.; Stotter, J.; Cvackova, Z.; Haymond, S.; Show, Y.; Swain, G.M. Conductive diamond thin-films in electrochemistry. Diam. Relat. Mater. 2003, 12, 1940-1949.

47. Granger, M.C.; Witek, M.; Xu, J.; Wang, J.; Hupert, M.; Hanks, A.; Koppang, M.D.; Butler, J.E.; Lucazeau, G.; Mermoux, M.; et al. Standard electrochemical behavior of thin-film electrodes. Anal. Chem. 2000, 72, 3793-3804.

48. Kiran, R.; deSanoit, J.; Scorsone, E. Procédé d'activation d'une électrode en diamant dopé. French Patent No. 1151341, 2011.

49. Colley, A.L.; Williams, C.G.; Johansson, U.D.; Newton, M.E.; Unwin, P.R.; Wilson, N.R; Macpherson, J.V. Examination of the spatially heterogeneous electroactivity of boron-doped diamond microarray electrodes. Anal. Chem. 2006, 78, 2539-2548.

50. Wilson, N.R.; Clewes, S.L.; Newton, M.E.; Unwin, P.R.; Macpherson, J.V. Impact of grain-dependent boron uptake on the electrochemical and electrical properties of polycrystalline boron doped diamond electrodes. J. Phys. Chem. B 2006, 110, 5639-5646.

(C) 2012 by the authors; licensee MDPI, Basel, Switzerland. This article is an open access article distributed under the terms and conditions of the Creative Commons Attribution license (http://creativecommons.org/licenses/by/3.0/). 